\title{
$>$ Uma Sutil Diferença: narrativas carcerárias em videoclipes de rappers brasileiros apenados e não apenados (1997 - 2000)
}

\author{
> A Slight Difference: prison narratives in sentenced and unsentenced \\ Brazilian rappers' videoclips (1997 - 2000)
}

\begin{abstract}
por Alisson Cruz Soledade
Doutorando em História na linha de pesquisa Histórias entrecruzadas de subjetividades, gênero e poder do Programa de Pós-graduação em História da Universidade Federal de Santa Catarina (UFSC), com bolsa Capes. E-mail: alissonsoledade@gmail.com. ORCID: 0000-0001-6929-7197.
\end{abstract}

\section{Resumo}

Em 1997, o grupo de rap Racionais Mc's gravou o primeiro videoclipe dentro de uma instituição prisional no Brasil. A partir disso, houve uma profusão de audiovisuais que narraram a vida dos presos nas instituições de privação de liberdade. Nesse contexto, foi perceptível que as narrativas sobre o cárcere não ficaram confinadas nas vozes, nos gestos e nas cabeças dos atores sócio-históricos fora do universo prisional. Grupos nascidos dentro das prisões, como o 509-E e o Detentos do Rap, também buscaram narrar a experiência do cárcere a partir da produção de videoclipes. Sendo assim, este trabalho busca analisar - a partir da linguagem videoclíptica - o modo como o cárcere foi narrado pelos grupos de rap brasileiros, situando as diferenças entre as narrativas produzidas por apenados e não apenados.

Palavras-chave: Videoclipe. RAP. Narrativas. Cárcere.

\begin{abstract}
In 1997, the rap group Racionais Mc's recorded Brazil's first video clip inside a penitentiary. Thereafter, there was a profusion of audiovisuals that narrated prisioners' lives in detention centers. In this context, it was possible to realize that the narratives about prison were not confined to the voices, gestures and heads of the social-historic actors outside the prison universe. Groups that were formed inside the prison, such as the 509-E and the Detentos do Rap, also sought to narrate the imprisonment experience through the production of video clips. Therefore, this article aims at analysing the way that prison was narrated by Brazilian rap groups - through the audiovisual language -, pointing out the differences between the narratives produced by sentenced and unsentenced prisoners.
\end{abstract}

Keywords: Video clip. RAP. Narratives. Prison. 


\section{Introdução ou apontamentos iniciais sobre narrativas carcerárias}

A produção de narrativas realizada por sujeitos em situação de privação de liberdade não é um fenômeno contemporâneo. No Brasil, relatos dessa espécie foram construídos já no período colonial, quando três estrangeiros contaram suas experiências de aprisionamento: Hans Staden, Bento Teixeira e Antônio Vieira. ${ }^{1}$ No império, Cipriano Barata produziu textos para o jornal Sentinella da Liberdade e também sobre os "Motivos de minha perseguição e desgraça em Pernambuco e Rio de Janeiro", no qual assinala que a causa principal das suas prisões e perseguições foram o fato dele ser maçom. ${ }^{2}$ No entanto, a obra que se tornou canônica sobre as experiências de encarceramento no Brasil foi Memórias do Cárcere de Graciliano Ramos.

Publicado postumamente na década de 1950, o texto foi produzido como memória dos dez meses em que Graciliano ficou encarcerado no presidio de Ilha Grande no Rio de Janeiro, acusado de fazer parte da Aliança Nacional Libertadora. Em Memórias do Cárcere, ele "narra com escrupulosa observação e profunda sondagem psicológica em mais de oitocentas páginas, fundindo o drama pessoal ao desastre coletivo da detenção"3.

De imediato, podemos assinalar que as narrativas carcerárias eram, sobretudo, escritas. Sejam poemas, textos para periódicos ou memórias. Esse cenário só se alteraria significativamente na década de 1990, quando artistas ligados à cultura Hip-Hop passaram a verbalizar as experiências de encarceramento - a princípio, de forma oral através das canções e, posteriormente, com aglutinação de imagens e canções nos videoclipes.

Diante disso, o presente trabalho busca analisar como o videoclipe se tornou uma linguagem eficaz para as narrativas de detentos sobre o universo das prisões no final da década de 1990, assim como as diferenças entre essas

\footnotetext{
${ }^{1}$ Ovidio Poli Junior, A pena e o cadafalso: observações sobre a literatura carcerária relativa ao período do Estado Novo, 2009.

${ }^{2}$ Ana Regina Rêgo, Sentinella da liberdade, a voz de Cipriano Barata, 2009.

${ }^{3}$ Ovidio Poli Junior, Op. Cit., 2009, p. 31.
} 
narrativas e aquelas produzidas fora do contexto prisional. Desse modo, a análise é centrada na comparação dos encadeamentos narrativos dos videoclipes e nos enunciados que os produzem. Esta é uma discussão introdutória que não possui o objetivo de refletir sobre o fenômeno social do encarceramento como política social e matriz primordial do sistema de justiça na contemporaneidade. $\mathrm{O}$ foco está na linguagem audiovisual enquanto nova possibilidade de produção de narrativas carcerárias.

\section{Rap}

O rap foi criado nos Estados Unidos, mais especificamente no Bronx, Nova York, em meados dos anos 1970 como uma cultura massivamente negra e juvenil. "É um dos elementos que compõem o movimento Hip Hop que se propagou por todo o mundo a partir da primeira metade dos anos 1980, incorporando a crítica ao modelo urbano e capitalista"4, tendo na música uma luta pela visibilização, no espaço público, das mazelas enfrentadas por setores da sociedade estadunidense. ${ }^{5}$

A chegada do Hip-Hop ao Brasil não demorou para acontecer: "em 1982 a juventude da periferia já dançava o break e ouvia os primeiros raps. Isso porque desde os anos 1970, na periferia das grandes cidades do país, eram comuns os bailes Black, com muito soul e funk"6. O rap não apenas deu continuidade a essa trilha, como foi responsável por abrir espaço para a construção de um vasto e denso repertório de representações sobre a sociedade brasileira, "articulando as narrativas das dores, das visões de mundo, da violência, do racismo, presentes na história contemporânea"7. Ele se consolidou como um gênero musical marcado

\footnotetext{
${ }^{4}$ Francisco José Gomes Damasceno, Sutil diferença: o movimento punk e o movimento hip hop em Fortaleza, 2011, p. 11.

${ }^{5}$ Anderson Grecco, Racionais MC's: música, mídia e crítica social em São Paulo, 2007.

${ }^{6}$ Rogério de Souza Pimentel apud Silva, A periferia pede passagem: trajetória social e intelectual de Mano Brown, 2012, p. 53.

${ }^{7}$ Roberto Camargos de Oliveira, Música e política: percepções da vida social brasileira no rap, 2011, p. 14.
} 
pelo engajamento social e tornou-se "uma importante via para adentrarmos no terreno dos conflitos, das tensões e do poder que opera desigualmente na vida social, conduzindo-nos a repensar os processos sócio históricos no Brasil”.

Nas décadas de 1980 e 1990, as músicas cantadas pelos rappers apresentavam, em sua grande maioria, temáticas que envolviam problemas sociais como o racismo, a violência e o desemprego. Contudo, é fundamental compreender que a música rap nasceu nos Estados Unidos em um determinado tempo e, ao ser praticada no Brasil, ela foi traduzida para a realidade local. Esse processo de tradução, que norteou o rap brasileiro e o distanciou daquele feito nos EUA, só foi possível graças aos encontros provenientes da globalização da cultura. Por um lado, as inovações técnicas, a indústria fonográfica estadunidense (principalmente da música negra) e o rap, nesse caso em especifico, alcançaram as periferias brasileiras e divulgaram os pensamentos e influências dos Panteras Negras, de Martin Luther King e, sobretudo, de Malcolm X; por outro lado, existiu também um processo de valorização do local a partir da elevação de personagens da história brasileira como Abdias do Nascimento, Carlos Marighella e, principalmente, Zumbi dos Palmares.

Ainda que as temáticas sociais tenham sido pilares de sustentação para a criação artística desses jovens, torna-se necessário compreender as diversas dimensões que compunham o cenário social que os envolvia - e que eles construíam nas suas canções. A dimensão poética composta pelas gírias e pelos temas políticos (como racismo e violência policial) apresentavam um imaginário urbano da maior cidade do país. Atravessada pela difusão do fatalismo neoliberal, a cidade de São Paulo era descrita pelos rappers como um local de abandono e desesperança, marcada por severas desigualdades sociais e raciais. Acerca desse fatalismo, Mariana Cortês afirma:

O contexto da redemocratização, durante os anos 1980, foram marcados por movimentos sociais que lutaram por direitos sociais e a concretização do sonho de construção de uma cidadania universal. Contudo, na década de 1990, a difusão do fatalismo neoliberal e o fim da

\footnotetext{
${ }^{8}$ Idem, Ibidem.
} 
"hipótese superadora" produziram resultados dramáticos na vida dos habitantes das periferias das grandes cidades. Observou-se a emergência de uma nova configuração societária nas periferias das grandes cidades, principalmente para o contexto de São Paulo: a estabilidade do emprego fordista cedeu lugar ao desemprego ou ao subemprego precário; o mundo do crime tornou-se uma alternativa sedutora para jovens que viram suas perspectivas de futuro fraturadas?.

O cenário de caos citadino encontrado nas obras dos rappers expõe, também, a elevação dos debates sobre a violência urbana no Brasil do final do século XX. O vertiginoso aumento dos casos de sequestro em São Paulo e os arrastões nas praias cariocas tomaram os noticiários, e os rappers não se furtaram de discutir o tema da violência, tão em pauta na sociedade brasileira. No entanto, é possível encontrar nas canções dos rappers uma abordagem divergente sobre a violência. Enquanto os principais jornais e programas televisivos se focavam nos crimes comuns do cotidiano ${ }^{10}$, nos raps eram encontradas inúmeras referências às violências perpetradas por agentes do Estado.

Foi nesse contexto sociocultural e de intenso debate sobre violência que o encarceramento passou a fazer parte do repertório temático dos rappers brasileiros. Ao longo da década de 1990, inúmeros grupos tematizaram o cárcere nas suas canções, mas foi com a produção do primeiro videoclipe em uma unidade prisional brasileira que as narrativas carcerárias alcançaram maior visibilidade.

\section{Os videoclipes de rapna MTV}

O ano era 1998 e o Racionais Mc's (formado pelos rappers Mano Brown, Ice Blue, Edi Rock e pelo DJ Kl Jay), grupo de rap de maior visibilidade na cena HipHop, lançava seu primeiro videoclipe depois de uma década de carreira. Intitulado Diário de um detento, o clipe alcançou enorme repercussão midiática e o topo das paradas na emissora Music Television Brasil (MTV). O sucesso do vídeo

\footnotetext{
${ }^{9}$ Mariana Côrtes, O dispositivo pentecostal e a agência dos governados, 2018, p. 32.

${ }^{10} \mathrm{Na}$ década de 1990, vários programas televisivos foram criados com a abordagem policial como tema principal. No nível nacional, Aqui Agora do SBT, Cidade Alerta da Rede Record e Linha Direta da Rede Globo apresentavam reportagens sobre crimes e ao mesmo tempo expunham seus posicionamentos referente à segurança pública.
} 
chegou ao seu ápice ainda em 1998, quando foi escolhido como melhor do ano pela audiência ${ }^{11}$ na premiação do Video Music Brasil realizado também pela MTV. No entanto, Diário de um detento não foi apenas o primeiro clipe produzido pelo Racionais Mc's. Ele também se tornou o primeiro videoclipe a ser gravado dentro de uma unidade prisional.

Foi no programa Yo! Mtv Raps da emissora MTV que o videoclipe do Racionais Mc's estreou. Esse veículo desempenhou um importante papel na popularização do rap na década de 1990 ao produzir a versão nacional do Yo!, programa homônimo da MTV americana que exibia clipes de rap. No Brasil, o programa inicialmente transmitia apenas as produções de rappers americanos até que, em 1994, Primo Preto - produtor musical de grupos de rap brasileiros e assistente da produção do programa - assumiu o comando da atração. Desse momento em diante, os brasileiros passaram a ter mais espaço no programa, que passou a exibir entrevistas, divulgar eventos de Hip-Hop, bem como veicular os videoclipes dos grupos nacionais ${ }^{12}$.

O videoclipe se tornou uma linguagem importantíssima do ponto de vista comercial. Ele possibilitava a extrapolação das redes de circulação às quais muitas gravadoras independentes não conseguiam atingir. Com a veiculação do audiovisual na MTV, os grupos conseguiam então projetar suas obras para um público bem maior do que a cena local. Um importante exemplo desse viés comercial foi a realização do videoclipe Isso aqui é uma guerra, pelo grupo Facção Central em 2000. Inicialmente, o vídeo deveria ter sido lançado em conjunto com o disco Versos sangrentos, em 1999, para potencializar a visibilidade do grupo, tanto do ponto de vista comercial quanto do empreendimento político desejado

\footnotetext{
${ }^{11}$ Essa era considerada a categoria mais importante da premiação por proporcionar ao público a oportunidade de escolher seu clipe de preferência. A vitória de Diário de um detento foi um sinal evidente de que o Racionais Mc's havia conseguido ultrapassar as portas da cultura Hip- Hop, alcançando outros públicos.

${ }^{12}$ É importante destacar que o rap brasileiro da década de 1990 era cantado por jovens oriundos das periferias dos centros urbanos do país e foi profundamente marcado pelo teor político. Suas influências eram as canções do gênero Knowledge Rap americano, as relações estabelecidas com coletivos de esquerda, o movimento negro e as ONG's de Direitos Humanos.
} 
por eles; contudo, devido ao atraso da produção, o videoclipe foi lançado apenas no ano seguinte. Após seis exibições, a MTV foi notificada pela justiça de que o clipe caracterizava apologia ao crime ${ }^{13}$. Assim, a produção do Facção Central saiu da grade de programação e nunca mais foi exibida em uma emissora de televisão. Somente em 2003, depois do encerramento do processo, o audiovisual foi liberado para veiculação; contudo, o grupo já havia produzido mais dois discos e o clipe, descontextualizado, não apresentava atrativos mercadológicos, tendo sido postado apenas em sites de divulgação da cultura Hip-Hop.

Para além das estratégias de divulgação comercial, o clipe é uma produção artística rica em associações de diversas matrizes e com possibilidades tão diversas que dificultam uma abordagem conceitual da expressão. Ela pode contar uma história por meio da narrativa, através da associação semiótica entre a imagem e a letra da canção (além da conexão do agenciamento das imagens a partir do ritmo sonoro), ou pode ser realizada de maneira completamente oposta, apresentando uma montagem totalmente experimental que não harmoniza a letra, a melodia e o ritmo da canção com a seleção das tomadas. Devido a essa segunda possibilidade de composição, "grande parte das abordagens sobre o videoclipe considera que este produto marca uma ruptura com a narrativa tradicional da literatura, cinema e tv, para apresentar uma organização estrutural, afiliada à fragmentação e ausência de linearidade"14.

Assim, o videoclipe se tornou, no final do século XX, uma expressão híbrida que congregou gramáticas das mais diversas, tais como a linguagem cinematográfica, a propaganda e as artes plásticas, alicerçando-as sempre ao

\footnotetext{
${ }^{13}$ Acerca da acusação de apologia ao crime e de todo o processo sofrido pelo Facção Central ver: Alisson Soledade, "Não deram faculdade pra eu me formar doutor então a rua me transformou no demônio rimador": a atuação intelectual dos rappers do Facção Central entre o discurso pedagógico e a apologia ao crime (1995-2001), 2017.

${ }^{14}$ Claudiane Carvalho, Narratividade e Videoclipe:Interação entre música e imagem nas três versões audiovisuais da canção "one" do U2, 2006, p. 58.
} 
suporte essencial da canção como forma de "vender um pacote completo: música e imagem do artista"15 e deste modo:

A invenção e popularização do videoclipe, na segunda metade do século XX contribuiu para o fortalecimento dessa nova conformação social. $\mathrm{O}$ videoclipe alargou os horizontes e ampliou as possibilidades de atuação dos jovens no cenário urbano e, num mesmo movimento, internacionalizou as suas reivindicações. As bases históricas da cultura hip hop, o desdobramento e a repercussão que cada um de seus elementos (o rap, o break e o grafite) alcançou junto aos jovens de todas as sociedades ocidentais passaram, então, pelo uso que eles fizeram dessa nova técnica de comunicação visual ${ }^{16}$.

Se no início do século XX, era a imagem que servia como referência para a construção da música, já que "as projeções de cinema eram acompanhadas por música [...] e a escolha da partitura estava relacionada ao teor das imagens apresentadas"17, com o surgimento do videoclipe essa referência se perdeu:

O videoclipe desenvolveu-se como um formato audiovisual impulsionado pelo avanço tecnológico das mídias e das consequências observadas nas linguagens e conteúdos produzidos. Ao unir a experimentação visual ao reino da música pop, a videomusica proporciona uma diferente concepção estética de consumo das produções musicais. Mostra-se como um amalgama de possibilidades audiovisuais, que mescla elementos das linguagens do cinema, TV e propaganda, além da música, é claro, aliados as possibilidades técnicas do vídeo e computação gráfica em plena expansão ${ }^{18}$.

Deste modo, o amálgama de possibilidades da linguagem videoclíptica pode ser percebido na sua historicidade e isto fica evidente também pela própria maneira como o produto era denominado: de início "foi chamado simplesmente de número musical. Depois, receberia o nome de promo, numa alusão direta à palavra promocional ${ }^{m 19}$. Apenas a partir dos anos 1980, o termo videoclipe passou a ser utilizado. Todavia, sua condição narrativa também sinalizava para a diversidade de possibilidades.

\footnotetext{
${ }^{15}$ Laura Correa, Breve história do videoclipe, 2006, p. 2.

${ }^{16}$ Rafael Lopes de Sousa, O movimento Hip Hop: a anti-cordialidade da "República dos Manos" e a estética da violência, 2009, p. 2 a 3.

${ }^{17}$ Thiago Soares, Videoclipe: o elogio da desarmonia, 2004, p. 21.

${ }^{18}$ Michele Kapp Trevisan, A era MTV, análise da estética de videoclipes (1984-2009), 2011, p. 9 a 10, grifo nosso.

${ }_{19}$ Thiago Soares, Op. Cit., p. 32.
} 
É inegável a característica do videoclipe como multiforme, um misto de densidade da composição e rarefação quanto à concretude da sua acepçãojustamente pela grande diversidade de linguagens que emprega na sua experimentação. No entanto, assim como Claudiane Carvalho, compreendo a necessidade de perceber que dentro dessa rarefação existem as permanências da narratividade na sua composição.

Os videoclipes dos rappers brasileiros, no final do século $\mathrm{XX}$, possuíam trama, ambientação, desenvolvimento, ação e conclusão em constante harmonia entre som e imagem. Assim, no rap, a "música é tanto o constituinte videoclíptico que evoca uma espécie ou efeito de narrativa, quanto responsável, de maneira geral, pelo ritmo da montagem do vídeo"20.

\section{Uma sutil diferença}

O universo das prisões se tornou uma das temáticas mais recorrentes do rap no Brasil. O próprio Racionais Mc's alcançou grande repercussão com a canção Homem na Estrada, que versava sobre o estigma carregado por apenados no Brasil - "A justiça criminal é implacável, tirou sua liberdade, família e moral, mesmo longe do sistema carcerário. Te chamarão pra sempre de ex-presidiário"21. Posteriormente, na canção Dia de visita, o grupo Realidade Cruel abordou a saudade e a expectativa dos presos com relação a visita dos familiares às prisões: "sinto uma grande vontade de chorar ao ver a minha mãe aqui vindo me visitar, talvez se eu tivesse pensado um pouco mais, talvez hoje eu não estaria atrás de uma cela num pátio de um presídio"22. Também o grupo Facção Central, na canção Prisioneiro do Passado, narrou a relação entre um ex-detento e a liberdade. É no emblemático refrão, "No Brasil uma vez no sistema carcerário pra sempre

\footnotetext{
${ }^{20}$ Thiago Soares, Ibidem, p. 40.

${ }^{21}$ Pedro Paulo Pereira, Homem na estrada, 1993, LP, Lado B, faixa 1.

${ }^{22}$ Realidade Cruel, Dia de Visita, 1998, 1 CD, faixa 3.
} 
presidiário!"23, que ele expressa algo bastante recorrente nas narrativas sobre o cárcere.

Inúmeros são os exemplos de grupos de rap que produziram canções sobre o cárcere, mas Diário de um detento se tornou paradigmático não somente pela tematização do encarceramento, mas também por ter sido o primeiro videoclipe gravado em uma unidade prisional. Nenhum dos quatro integrantes do Racionais Mc's era detento. Sendo assim, que tipo de narrativa foi construída pelos rappers para que seu videoclipe ganhasse tanta repercussão?

Antes mesmo da sua primeira exibição, o portal online do jornal Folha de São Paulo já destacava a novidade:

Em "Diário de um Detento", primeiro videoclipe da história do grupo paulistano de rap Racionais MC's, o cantor Mano Brown veste a roupa de um presidiário que sobreviveu ao massacre do Carandiru e, de volta ao palco dos acontecimentos, reconta a chacina. A estréia (sic) será no sábado, às $12 \mathrm{~h} 30$, no programa de rap "Yo!" da MTV. A música faz parte do mais recente disco dos Racionais, "Sobrevivendo no Inferno" (mais de 200 mil cópias vendidas desde novembro do ano passado). "Diário de um Detento" foi filmado no "país das calças bege" (o Carandiru, numa referência ao uniforme dos presos), palco da tragédia de 2 de outubro de 1992, quando a invasão da Polícia Militar no pavilhão 9 da cadeia resultou na morte de 111 detentos. O clima realista das imagens, em oito minutos de duração, transforma "Diário de um Detento" num minidocumentário sobre a chacina, na versão de um sobrevivente. A letra da música nasceu do relato de um preso identificado apenas como Jocenir [...] Brown tinha ido ao Carandiru participar de um jogo de futebol quando o detento lhe entregou a letra, depois acrescida de outras histórias que o rapper recolheu de cartas enviadas por presos ${ }^{24}$.

Na narrativa de Diário de um detento - repleta de referências autobiográficas, segundo a reportagem da Folha - "Brown 'declama' o massacre em 'flashback' como se estivesse lendo seu diário"25. Essas referências seriam as cartas enviadas pelos detentos ao grupo e o relato de Jocenir. Desta maneira, o videoclipe teria se transformado em um minidocumentário que apresentava uma versão do massacre.

\footnotetext{
${ }^{23}$ Eduardo Taddeo, Prisioneiro do Passado, 1999, 1 CD, faixa 14.

${ }^{24}$ Fernando Oliva, 'DETENTO' Mano Brown filma no Carandiru, 1998.

${ }^{25}$ Idem.
} 
Apesar da recorrente definição de que o rap havia se tornado uma linguagem intrinsecamente ligada à condição representativa da realidade, a canção e, por conseguinte, o videoclipe não eram decalque de uma realidade exterior. Como dito anteriormente, os audiovisuais produzidos tendo como referência os raps possuíam trama, ambientação e desenvolvimento. Diante disso, era notória a montagem do videoclipe. E enquanto montagem e composição, inegavelmente, o clipe possuía o corte ficcional:

\begin{abstract}
Os figurantes que atuam no clipe ou são presos mesmo (fizeram questão de aparecer ao lado do ídolo Mano Brown) ou amigos do rapper no Capão Redondo, zona sul, periferia de São Paulo. Quase totalmente em preto-ebranco, abusando da câmera lenta, o videoclipe é cru e direto como a letra da canção. "Diário de um Detento" usa ainda fotografias captadas durante as filmagens, nos dias 3 e 12 de dezembro de 1997. As imagens, da fotógrafa Rachel Guedes, retratam o dia-a-dia dos presos: lutando capoeira, fazendo musculação, costurando sapatos ${ }^{26}$.
\end{abstract}

Deste modo, a partir da compreensão de que o videoclipe é uma montagem sobre o acontecimento do Carandiru, pôde-se perceber como as imagens e a música apresentavam uma narrativa sobre o cárcere.

O clipe se inicia com quatro crianças jogando dominó enquanto outras brincam com cordas ao fundo. A imagem é cortada e, agora, o cenário é uma cela onde quatro homens também jogam dominó e um os assiste. Enquanto a primeira imagem é em preto e branco, a segunda é colorida - sinalizando a passagem de tempo. Concomitante ao take, o narrador situa: São Paulo, dia primeiro de outubro de 1992. Oito horas da manhã. A partir daí a música começa com o ritmo cadenciado, composta pelo sample das músicas Easin' In de Edwin Starr e Mother's Son de Curtis Mayfield. Na imagem, o personagem encenado pelo rapper Mano Brown aparece escrevendo em um caderno enquanto é enunciado: "Você não sabe como é caminhar com a cabeça na mira de uma HK. Metralhadora alemã ou de Israel. Estraçalha ladrão que nem papel”27.

\footnotetext{
${ }^{26}$ Idem.

${ }^{27}$ MundoClipsBr, Diário de um detento Racionais Mc's (Clip Oficial), [1997] 2012.
} 
O desenvolvimento da narrativa se dá pelo deslocamento do narrador. Esse deslocamento deve ser entendido no nível poético, quando são enunciados diversos elementos da vida na prisão - como os guardas, os muros, a tensão envolvendo os detentos - mas também as preocupações com o mundo para além dos muros, principalmente sobre as condições de membros da família. Ele deve ser compreendido também no quesito do trânsito do personagem entre celas, corredores e pátios. Todo esse deslocamento compõe o cenário da prisão antes do conflito entre detentos, o qual culmina na invasão da polícia e no massacre.

O clipe Diário de um detento não é linear. Nele, foram articulados elementos dos mais diversos da vida do encarcerado, como forma de apresentar um tipo de conscientização a partir da narrativa, característica marcante dos raps brasileiros do período. Isso ficou mais evidente com a cena dos integrantes do grupo dentro de um carro observando um assalto na rua, enquanto era verbalizado que "Nada deixa um homem mais doente que o abandono dos parentes. Aí moleque, então, você quer o que? A vaga está lá esperando você [...] a vida do crime é sem futuro" 28 .

Assim, apesar da recorrente afirmação de que o videoclipe Diário de um detento tratava de uma versão sobre o Carandiru, é possível perceber que o clipe se reportava mais para uma narrativa sobre cárcere que havia aglutinado prefigurações para sua montagem do audiovisual coerente com a linguagem artística do rap. Isto é, o videoclipe, antes de se reportar ao massacre do Carandiru como fato, era uma produção artística que possuía coerência com a cultura da qual fazia parte, o Hip-Hop. Objetivando-se assim produzir não um relato, mas uma arte preocupada com uma projeção pedagógica, tendo como principal endereçamento os manos fora da cadeia. Essa é a principal característica das narrativas sobre o cárcere produzidas por pessoas extramuros.

Não foram apenas os artistas não apenados que apresentaram narrativas sobre as prisões. No final da década de 1990, os grupos Detentos do Rap (DTS) e o

${ }^{28}$ Idem. 
509-E foram formados na Casa de Detenção de São Paulo, aprofundando ainda mais as obras musicais sobre a vida nas unidades prisionais, a partir das falas dos próprios atores em situação de privação de liberdade. Os relatos desses grupos voltaram-se para a relação entre o encarceramento e a liberdade - "tem muito mano certo no movimento errado, hoje eu sei que sem ela é embaçado, mesmo na favela dê valor a ela [...] ela não é a vida, ela não é a morte, ela é meu sonho, [...] pela janela eu vejo cara dela, esperança do mundo, meu sonho, liberdade"29 - e para o tenso cotidiano das prisões - "aqui é foda não tem comédia, o clima é de tensão, maldade, inveja. A destruição mora nesse lugar e mesmo assim não deixei me levar. Soube chegar na humildade e pá. Faça o contrário e caro pode te custar"30. Busca-se, assim, sempre apresentar o caráter desumano desses cenários e caracterizá-los como espaços de profunda degradação da condição humana.

O DTS produziu seu primeiro videoclipe em 1998. Intitulado Casa cheia, a criação audiovisual dos detentos não buscou uma articulação total entre imagem e letra da canção. Ainda assim, é possível perceber a narratividade da obra. De maneira dispersa e fragmentada - possibilidade que fez o videoclipe ser compreendido como uma linguagem artística pós-moderna -, Casa cheia expunha as contradições que envolviam a ressocialização dos presos e sua efetividade.

Na canção, entoada em primeira pessoa e com ritmo de aceleração moderada, é verbalizada a superlotação da prisão, o consumo de drogas e a violência por parte da polícia, mas também entre os presos. É destacada a contradição de todo esse desenvolvimento do cenário prisional com a enunciação: "falam que aqui estão nos educando, mas é mentira, na verdade estão nos marginalizando"31. Enquanto esses aspectos são verbalizados, as imagens apresentam inicialmente a prisão vista de cima. Posteriormente, os rappers aparecem cantando dentro da unidade prisional enquanto caminham entre os pavilhões. Nesse deslocamento dos rappers, são expostos elementos que não

\footnotetext{
${ }^{29}$ Detentos do Rap, Apenas mais um, 2001, 1 CD, faixa 3.

30 509-E, Oitavo anjo, 2000, 1 CD, faixa 6.

${ }^{31}$ Detentos do Rap Ofc, Casa cheia, 1998, [1998] 2013.
} 
fazem parte daquilo que está sendo verbalizado na letra, a exemplo dos dançarinos de break em performance nos corredores. Ainda assim, o videoclipe é composto de cenas de celas lotadas, outras em que presos (encenados) aparecem nus, simulando uma blitz do choque dentro da prisão, além de cenas de consumo de entorpecentes.

Deste modo, a narrativa composta pelo Detentos do Rap expõe a contradição entre a ressocialização e as condições degradantes da vida dos presos na unidade prisional. $\mathrm{O}$ tom de denúncia está focado nas próprias questões do preso e não em uma pedagogia para pessoas fora do universo das prisões, como no videoclipe do Racionais Mc's.

Em uma cela, três pessoas conversam. Um detento apresenta a rima que acabou de produzir para um rap. É com esse diálogo que o primeiro videoclipe de Dexter e Afro-X, rappers do grupo 509-E, se inicia. O diálogo é tanto sobre a música quanto sobre a dificuldade encontrada por eles para poder criar suas canções, já que "os caras não deixam entrar um som com fita, com $\mathrm{CD}$, pra nós fazer (sic)... mas vai rimando, vai rimando [...] eu vou ouvir um som"32. O som que Dexter começa a escutar é justamente a música que faz parte do videoclipe, Oitavo anjo.

O elemento musical do videoclipe possui um tom grave e cadenciado. A montagem da base sonora, a partir da congregação de trechos das canções Porque é proibido pisar na grama de Jorge Ben e What Becomes of the Brokenhearted de Jimmy Ruffin, com o crocito de corvo cria um efeito de tensão. A poesia expressa as vicissitudes da cadeia. A tensão, a violência e a necessidade de se reconhecer os códigos éticos que regem a prisão. É nesse quesito que a narrativa do videoclipe, como um todo, é sinalizada no cruzamento com as imagens que são exibidas; isto é, assim como no videoclipe do DTS, não existe uma linearidade na criação audiovisual do 509-E. Mas enquanto os sons apontam esses elementos éticos e a sonoridade cria um ambiente de tensão, as imagens exibem cenas do

\footnotetext{
32 Jorge Pinho, 509-E, Oitavo anjo, [2000] 2007.
} 
rapper Dexter cantando no pátio da prisão, pessoas fazendo exercícios físicos, jogando futebol, costurando bolas, momentos de rebelião e brigas entre detentos.

A narrativa do videoclipe apresenta, então, os elementos necessários para a superação das agruras da vida no cárcere. As imagens do rapper, ao longo do videoclipe, projetam a ideia de que ele conseguira superar os problemas elencados na poesia e na imagem, encerrando a narrativa com a enunciação:

\author{
Ei mano dê nos (sic) ouvidos \\ Não seja você mesmo seu próprio inimigo \\ Termino por aqui espero que me entenda \\ Pra que depois não se arrependa \\ É tudo no seu nome, decide aí \\ Escolha seu caminho, o exemplo tá aqui \\ Obrigado meu deus por me guiar \\ Só em ti tenho forças pra lutar ${ }^{33}$.
}

O foco do videoclipe do 509-E é o próprio preso. O protagonismo da narrativa é do detento. Isso é visível tanto do ponto de vista da centralidade de Dexter nas imagens quanto das enunciações sobre os artifícios que os encarcerados podem encontrar para superar a tensão que é a vida na prisão.

Por meio dos exemplos mencionados, é perceptível que o videoclipe se tornou uma linguagem importante para a produção de narrativas carcerárias no Brasil no final da década de 1990. De uma forma inicial e impactante, o Racionais Mc's ganhou notoriedade com seu Diário de um detento, que construiu uma narrativa pedagógica sobre o cárcere a partir da incorporação de testemunhos de detentos e das encenações e montagens nas cenas do videoclipe. Essa pedagogia se projetava para o público externo às prisões. Essa é a sutil diferença em relação às narrativas carcerárias produzidas inteiramente por apenados. Os videoclipes do Detentos do Rap e do 509-E deram centralidade e protagonismo à prisão a partir do ponto de vista dos próprios presos, ao denunciar as contradições do sistema prisional e ao expor os caminhos para uma convivência ética no cárcere.

${ }^{33}$ Idem. 


\section{Considerações finais}

No final da década de 1990 e início dos anos 2000, filmes foram produzidos sobre o massacre que ocorreu na Casa de Detenção de São Paulo (em 1992); documentários, canções e videoclipes foram criados sobre a vida em unidades prisionais no Brasil. Foi um período de salutar crescimento do interesse da sociedade brasileira pelo tema prisional:

A partir de 2000, livros escritos por homens presos ou recém-saídos da prisão ganharam as páginas dos suplementos culturais dos grandes jornais e revistas, fosse porque publicados por casas editoriais médias ou grandes, fosse porque parece haver, hoje em dia, maior curiosidade em torno da vida na prisão ${ }^{34}$.

Com efeito, pelo delineado até aqui, o interesse "em torno da vida na prisão" não é algo localizado a partir dos anos 2000 . As canções e os videoclipes dos grupos de rap atravessaram os anos 1990 tematizando a prisão e também sendo produzidos por detentos. Até mesmo se dermos centralidade à linguagem escrita, o livro Estação Carandiru, do médico Drauzio Varella, foi lançado na mesma década. No entanto, é possível perceber que as linguagens não escritas, principalmente as canções e os videoclipes, ainda sofrem com o não reconhecimento das suas construções narrativas.

Apesar disso, inegavelmente o videoclipe se tornou uma importante linguagem artística contemporânea, capaz de apontar elementos importantes sobre as narrativas carcerárias produzidas por presos ou nascidas da incorporação de relatos de presos, como no caso do clipe Diário de um detento.

A MTV teve papel importante na divulgação dessa linguagem, nos anos 1990, ao exibir eventos específicos sobre o rap, gênero musical responsável por hegemonizar as narrativas videoclípticas produzidas por apenados no Brasil. Foi no Yo! Mtv raps que Diário de um detento do Racionais Mc's e Casa cheia do

\footnotetext{
${ }^{34}$ Maria Rita Palmeira, Cada história, uma sentença: narrativas contemporâneas do cárcere brasileiro, 2009, p. 8.
} 
Detentos do Rap - em 1998 -, bem como Oitavo anjo do 509-E - em 2000 -, foram exibidos. Outros videoclipes foram produzidos sobre o tema no mesmo período, mas essas três foram as obras de maior impacto para a cena Hip-Hop e para o público geral, como no caso do clipe do Racionais.

Portanto, os videoclipes de rappers brasileiros se tornaram uma importante linguagem para a construção de narrativas carcerárias na contemporaneidade, através da incorporação de testemunhos dos presos e/ou a partir das próprias experiências no sistema prisional. Essas narrativas, para além das dimensões culturais, transformaram-se em importantes sinais das contradições que envolviam o objetivo das unidades prisionais e a sua real execução. Essa apreensão se tornou possível graças à criatividade dos presos em comungar a atividade artística ao posicionamento político frente às vicissitudes da vida na prisão.

\section{Referências}

APENAS MAIS UM. [Intérprete]: Detentos do Rap. In: QUEBRANDO as algemas do preconceito. São Paulo: Sky Blue Music, 2001.1 CD, faixa 3.

CARVALHO, Claudiane. Narratividade e Videoclipe: Interação entre música e imagem nas três versões audiovisuais da canção "one" do U2. 2006. $176 f$.

Dissertação (Mestrado em Comunicação) - Faculdade de Comunicação, Universidade Federal da Bahia, Salvador, BA.

CORREA, Laura Josani Andrade. Breve história do videoclipe. In: Congresso Brasileiro de Ciências da Comunicação da Região Centro-Oeste, 8., 2006, Cuiabá. Mato Grosso: Intercom - Sociedade Brasileira de Estudos Interdisciplinares da Comunicação, 2006.

CÔRTES, Mariana. O dispositivo pentecostal e a agência dos governados. Em Debate, Belo Horizonte, v.10, n.1, p.31-38, 2018. 
DAMASCENO, Francisco José Gomes. Sutil diferença: o movimento punk e o movimento hip hop em Fortaleza - grupos mistos no universo citadino contemporâneo. Fortaleza: EdUECE, 2011.

DETENTOS DO RAP OFC, Casa cheia 1998, [1998] 2013. Atualizado em 21 ago. 2019. Disponível em: https://www.youtube.com/watch?v=Uov-P8fCXv4. Acesso em: 06 jun. 2017

DIA DE VISITA. [Interprete]: Realidade Cruel. In: SÓ sangue bom. São Paulo: Face da Morte Produções, 1998.1 CD, faixa 3.

GRECCO, Anderson. Racionais MC's: música, mídia e crítica social em São Paulo. 2007. 226f. Dissertação (Mestrado em História) - Pontifícia Universidade Católica de São Paulo, São Paulo, SP.

HOMEM NA ESTRADA. [Compositor]: Pedro Paulo Pereira. [Intérprete]: Racionais Mc's. In: RAIO X do Brasil. São Paulo: Zimbabwe, 1993. Disco vinil, lado B, faixa 1.

JORGE PINHO, 509E Oitavo Anjo, [2000] 2007. Atualizado em 21 ago. 2019. Disponível em: https://www.youtube.com/watch?v=GkWOrznOTN8. Acesso em: 06 jun. 2017.

MUNDOCLIPSBR, DIÁRIO de um detento Racionais Mc's (Clip Oficial), [1997] 2012. Atualizado em 21 ago. 2019. Disponível em:

https://www.youtube.com/watch?v=er-bYI9-3hM\&t=23s. Acesso em: 05 jun. 2017.

OITAVO ANJO. [Intérprete]: 509-E. In: PROVÉRBIOS 13. São Paulo: Atração, 2000.1 CD, faixa 6.

OLIVA, Fernando. 'DETENTO' Mano Brown filma no Carandiru, 1998. Atualizado em 21 ago. 2019. Disponível em: 
http://www1.folha.uol.com.br/fsp/ilustrad/fq29019803.html. Acesso em: 05 jun. 2017.

OLIVEIRA, Roberto Camargos de. Música e política: percepções da vida social brasileira no rap. 2011. 145f. Dissertação (Mestrado em História) - Universidade Federal de Uberlândia, Uberlândia, MG.

PALMEIRA, Maria Rita. Cada história, uma sentença: narrativas contemporâneas do cárcere brasileiro. 2009. 180f. Tese (Doutorado em Literatura Brasileira) - Faculdade de Filosofia, Letras e Ciências Humanas, Universidade de São Paulo, São Paulo, SP.

POLI JUNIOR, Ovidio. A pena e o cadafalso: observações sobre a literatura carcerária relativa ao período do Estado Novo. 2009. 189f. Tese (Doutorado em Literatura Brasileira) - Faculdade de Filosofia, Letras e Ciências Humanas, Universidade de São Paulo, São Paulo, SP.

PRISIONEIRO DO PASSADO. [Compositor]: Eduardo Taddeo. [Intérprete]: Facção Central. In: VERSOS Sangrentos. São Paulo: Sky Blue, 1999.1 CD, Faixa 14.

RÊGO, Ana Regina. Sentinella da liberdade, a voz de cipriano barata. In: ENCONTRO NACIONAL DE HISTÓRIA DA MÍDIA, 7., 2009, Fortaleza. VII Encontro Nacional de História da Mídia, Fortaleza, 2009.

SILVA, Rogério de Souza. A periferia pede passagem: trajetória social e intelectual de Mano Brown. 2012. 302f. Tese (Doutorado em Sociologia) Instituto de Filosofia e Ciências Humanas, Universidade Estadual de Campinas, Campinas, SP.

SOARES, Thiago. Videoclipe: o elogio da desarmonia. João Pessoa: LivroRápido, 2004.

SOLEDADE, Alisson Cruz. "Não deram faculdade pra eu me formar doutor então a rua me transformou no demônio rimador": a atuação intelectual dos rappers do 
Facção Central entre o discurso pedagógico e a apologia ao crime (1995-2001). 2017. 174f. Dissertação (Mestrado em História) - Centro de Humanidades, Universidade Estadual do Ceará, Fortaleza, CE.

SOUSA, Rafael Lopes de. O movimento Hip Hop: a anti-cordialidade da "República dos Manos" e a estética da violência. 2009. 236f. Tese (Doutorado em História) - Instituto de Filosofia e Ciências Humanas, Universidade Estadual de Campinas, Campinas, SP.

TREVISAN, Michele Kapp. A era MTV, análise da estética de videoclipes (19842009). 2011. 265f. Tese (Doutorado em Comunicação Social) - Faculdade de Comunicação Social, Pontifícia Universidade Católica do Rio Grande do Sul, Porto Alegre, RS.

\section{Referência para citação deste artigo}

SOLEDADE, Alisson. Uma Sutil Diferença: narrativas carcerárias em videoclipes de rappers brasileiros apenados e não apenados (1997 - 2000). Revista PHILIA |Filosofia, Literatura \& Arte, Porto Alegre, volume 1, número 2, p. 3 - 21, outubro de 2019. 